\title{
La fotografía como permanencia de lo efímero en la obra de Edwin Jimeno*
}

\author{
Pedro Román Villalba Granados*
}

\begin{abstract}
Recibido: 17 de marzo de 2015
Evaluado: 23 de abril de 2015

Aceptado: 7 de mayo de 2015
\end{abstract}

\section{RESUMEN}

El performance ha sido concebido y visto desde sus inicios como una manifestación artística que tiene como característica principal lo efímero de sus acciones, las cuales son conocidas por espectadores que en su mayoría están ausentes de la acción, solo la experimentan por medio de la fotografía o videos. De esta manera, el propósito de esta investigación es indagar sobre la relación entre la práctica performática como manifestación artística y la fotografía como práctica, que no solo se proyecta como documentación y registro, sino que en su participación frente al desarrollo de la obra performática es mucho más activa; de esta manera, se lleva a artistas como Edwin Jimeno a explorar otros campos que le permitirán iniciar procesos que hasta el momento no había abordado.

Palabras clave: performance, imagen, fotografía, efímero.

\footnotetext{
Artículo de reflexión, producto del proyecto de investigación para obtener el título de magíster en Historia del Arte, de la Universidad de Antioquia. Cómo citar este artículo: Villalba Granados, P.R. (2015). La fotografía como permanencia de lo efímero en la obra de Edwin Jimeno. Hallazgos, 12(24), 49-61 (doi: http://dx.doi.org/10.15332/s1794-3841.2015.0024.03).

** Artista Plástico; aspirante a magíster en Historia del Arte, Universidad de Antioquia (Colombia). Docente de la Institución Universitaria Bellas Artes y Ciencias de Bolivar (Colombia). Correo electrónico: ap_pedrovillalba@unibac.edu.co
} 


\title{
Photography as permanence of the ephemeral in Edwin Jimeno's work
}

\begin{abstract}
The performance has been conceived and viewed from its inception as an art form, whose main characteristic is the ephemeral nature of their actions, which are known to viewers who are mostly absent from the action, only through photography or videos. Thus, this research aims to investigate the relationship between performative practice as an art form and photography as a practice that not only is projected as documentation and registration, but also in its participation in the performance work in a way that it is much more active, leading artists, such as Edwin Jimeno, to explore other fields that allow them to initiate in processes that until now had not addressed.
\end{abstract} Received: March 17, 2015 Evaluated: April 23,2015 Accepted: May 7,2015

Keywords: Performance, image, photography, ephemeral. 


\section{A fotografia como permanência do e efêmero na obra de Edwin Jimeno}

Recebido: 17 de março de 2015

Avaliado: 23 de abril de 2015 Aceito: 7 de maio de 2015

\section{Resumo}

A performance tem sido concebida e vista desde o seus inicios como uma manifestação artística que tem como característica principal o efêmero de suas ações, as quais são conhecidas por espectadores que em sua maioria estão ausentes da ação, somente a experimentam por meio da fotografia o vídeos. De esta forma, o propósito de esta pesquisa é indagar sobre a relação entre a prática da performance como manifestação artística e a fotografia como prática, que não somente projeta-se como documentação e registro, senão que a sua participação no desenvolvimento da obra da performance é muito más ativa; de esta forma, leva artistas como Edwin Jimeno a explorar outros campos que o permitirá iniciar processos que até o momento não tinha abordado.

Palavras-chave: performance, imagem, fotografia, efêmero. 


\section{INTRODUCCIÓN. Acerca de Edwin Jimeno}

Aunque el performance se tiene en la historia del arte como algo relativamente nuevo, dado que surge entre los años cincuenta y sesenta del siglo $X X$, es sabido que el cuerpo siempre ha sido usado como herramienta comunicativa de una idea, y la acción del mismo como elemento dialógico que le permite al observador establecer un punto de comparación e interpretación de la realidad a través de cada uno de sus movimientos o gestualidades. Esto es algo que se puede ver en obras como las de Miguel Ángel Bounarotti, y el lenguaje que desarrolla en cada una de las acciones expuestas por los personajes a través del lenguaje de las manos, en la obra de Auguste Rodin que tienen implícito todo el drama de la teatralidad, en las proyecciones psicológicas de la escultura de Ron Mueck o en las escenas de caza del arte rupestre. En fin, el cuerpo como motivo para establecer parámetros en el pensamiento de un artista ha estado latente en las diferentes prácticas artísticas o culturales conocidas hasta el momento.

Edwin Jimeno es un artista que obedece a esta corriente en la cual el cuerpo se plantea como objeto de estudio, como obra de arte misma. Jimeno, nacido en Santa Marta en 1974, trae desde niño una serie de influencias que definen a posteridad su proceso y práctica artística. El juego, la religión y el teatro son las principales prácticas que lo llevarán a reflexionar sobre la posibilidad de establecer un proceso de creación en el cual el cuerpo es el elemento principal de su propuesta. El juego visto por el artista como la posibilidad de explorar el cuerpo, sus límites y su resistencia, su visión teológica frente al placer y al dolor, y el teatro como experiencia frente a la puesta en escena y el manejo del espacio a través del objeto y el cuerpo mismo.

Ingresa al programa de Licenciatura en Artes Plásticas de la Universidad de Magdalena en 1994, donde empezaría un proceso de decantación artística, extrayendo lo mejor de sí mismo para poder consolidar lo que es hoy su obra. Se inicia participando en el VII Salón Regional de Artistas, zona norte, que tuvo como sede la Fundación Museo Bolivariano de Arte Contemporáneo en Santa Marta en 1977, con la obra Nicho humano, una instalación performática que dentro de sus aspectos formales estaba compuesta por un rectángulo hecho con seis galones de arena de mar húmeda, con el fin de imprimir sobre la arena las huellas de sus pies, posándose posteriormente el artista en la primera mitad de este a manera de escultura, dado que se encontraba cubierto de arcilla; de esta manera pasa a ser una pieza más de la instalación, y genera un engaño visual para quien lo contempla. Al lado izquierdo hay una piedra sobre la cual reposa su brazo, que recuerda los anexos esculpidos al pie de algunas esculturas, como es al caso del David de Miguel Ángel; esto con el fin de mantener el equilibrio de la pieza,

Con este trabajo, el artista aborda el tema del patrimonio como parte de la memoria humana, del ecosistema, de la casa y del espacio donde se desarrolla el individuo. Es un llamado de atención para mostrar al hombre en su estado natural y para reflexionar sobre la relación del ser humano con su hábitat y consigo mismo (Sotelo, 2000, p. 5).

El primer premio que recibió Jimeno del VII Salón Regional de Artistas, región Caribe 
(1997), sirve como plataforma para llegar al XXXVII Salón Nacional de Artistas en 1998, en el cual obtuvo el segundo premio. Estos son los primeros reconocimientos para Jimeno como Artista Plástico, que fueron un aliciente para el inicio de una carrera. De esta forma, en su obra temprana el artista genera un proceso en el que se ve reflejada toda una serie de eventualidades que están sujetas a sus experiencias de vida. Estas manifestaciones, las cuales se revelan en la obra a través del cuerpo a manera de rasgos de una memoria somática, es decir, aquellas vivencias que están en la memoria del individuo y que se manifiestan en cada acción que genera con el cuerpo una herramienta que determina un límite de resistencia entre un territorio interno y uno externo, le dan cierta transcendencia al cuerpo como obra de arte, a través de la acción como recurso estético. Este proceso descrito puede ser visto como el motor fundamental del proceso de maduración conceptual de la obra de Jimeno.

Una de las influencias artísticas que encontramos en Edwin Jimeno está en las obras de Gilbert y George desde la concepción que estos tienen del cuerpo como escultura viva, como lo es en su obra The Singing Sculpture, en la que se convierten a sí mismos en piezas de arte, idea que tomaría Jimeno para su Nicho humano. En esta obra se exhibe a sí mismo inmóvil, cual objeto escultórico que evoca un espacio de recogimiento donde el tiempo parece detenerse para abrir paso a la imaginación del espectador. Así mismo, están las obras de María Teresa Hincapié, con quien tuvo la oportunidad de tomar un taller de performance en Santa Marta. La obra de Hincapié titulada Una cosa es una cosa de 1990 (que la hizo ganadora del primer premio del XXXIII Salón Nacional de Artistas) impactó a Jimeno,. La ritualidad, lo sagrado, el uso del objeto cotidiano y la introspección que asume la artista fueron elementos claves sobre los que Jimeno reflexionaría para el desarrollo de su obra posterior.

En 2000 Jimeno participó en el Proyecto Pentágono, el cual se centraba en la investigación sobre el arte contemporáneo en Colombia. Actos de Fabulación: arte, cuerpo $y$ pensamiento es el nombre del proceso investigativo y de acción performatica que dirigía Consuelo Pabón, en el que participó Jimeno con su obra El nacimiento,

El artista aborda el tema de la memoria y retoma creencias y supersticiones, vinculadas al momento de nacer, que identifica al hombre del Caribe. Pero estas creencias no sólo nos muestran los comportamientos sociales y culturales de su región sino también los instantes lúdicos que acompañan al nacimiento: adivinar de qué sexo será, cuando nacerá, o aplicarse el cebo del neonato en la piel para rejuvenecer etc. De esta forma el artista pretende crear un espacio de reflexión que no solo lleva al hombre a mirar sus costumbres, sino a ampliar las percepciones para apreciar y amar su entorno (Pabón, 2000, p. 55).

Eso es solo una parte del constante proceso de creación por parte de Jimeno en relación con la obra de arte. Lo que realmente compete en estos momentos es la fotografía como elemento que le permite a Jimeno desarrollar sus acciones como manifestaciones del instante, es decir, a manera de obra efímera y un proceso que asume de forma 
intencional; con esto establece un producto de permanencia con el que logra ingresar en algunos de los circuitos del arte en los cuales no había estado inmerso hasta ese momento.

La obra de Jimeno lleva a establecer una serie de reflexiones sobre lo permanente y lo etéreo, entre la función del fotógrafo como sujeto que de manera espontánea documenta o registra una acción generada por el artista en el momento de la exhibición y su participación activa en acuerdo mutuo con el artista mismo, para establecer un proceso de estudio de recopilación histórica y narrativa que le dará otro sentido no solo a la acción del artista del performance, sino también al artista fotógrafo. En ese sentido, el objetivo por seguir es analizar dicho proceso para establecer la participación del fotógrafo en este tipo de acciones, pero sobre todo el resultado propuesto por el artista y su ingreso a un circuito que está dado en ocasiones solo para obras de arte con un carácter de permanencia, de objetualidad o tangible, donde la imagen permanece a través de la materialidad.

De esta manera, se emprende un camino en el cual se asume un análisis de la obra de arte de Jimeno. Desde la sección primera, La fotografía como permanencia de lo efímero, se mira la fotografía como una herramienta que independientemente de la intención del fotógrafo. Esta capta una serie de acciones dadas por el ser humano y permite que ese instante permanezca como imagen, haciéndose parte fundamental de la memoria del ser humano, pudiéndose realizar en esta una serie de estudios de manera pública o privada. Desde la sección La fotografía como documentación y registro, se mira la fotografía como acción que puede procesar algo sin un fin concreto, que registra un instante presencial pero que tiene un carácter social lo suficientemente fuerte como para hacer parte de la memoria, estableciéndose como una práctica que configura realidades por medio del lente de manera subjetiva. Desde La fotografía como recopilación histórica narrativa, se muestra la fotografía como un proceso de recopilación de información visual en el cual existe una intencionalidad en relación con el sujeto fotografiado que en este caso es el artista del performance, haciendo de la práctica fotográfica una práctica de configuración de realidades con un carácter totalmente objetivo. Por último, en La introducción del performance al mercado a través de la fotografía, esta última es vista como una necesidad del artista para incluirse en los diferentes circuitos del arte, donde la obra de arte debe tener cierto carácter de permanencia para hacer parte de un flujo mercantil, y donde, al igual que cualquier producto, es vista como un bien de consumo, algo que lleva al artista a replantearse a sí mismo como obra de arte, a replantear su escenario, su espacio, la imagen que pasa de lo efímero a lo permanente y por ende la esteticidad de la obra misma.

\section{LA FOTOGRAFía COMO PERMANENCIA DE LO EFíMERO}

La fotografía es una herramienta que ha servido de apoyo para la documentación y registro de obras efímeras como acciones originales e independientes a la fotografía misma, como es el caso del performance, que se convierte en un elemento fundamental para la permanencia de las mismas. De igual manera, su antítesis, la fotografía aprovechada bajo la práctica de recopilación histórica o narrativa de la obra, es decir, performance creados para 
ser documentados de una manera específica, editados en su desarrollo, donde no solo juega la acción ejecutada por el artista plástico, sino también la acción ejecutada desde la mirada del artista fotógrafo; "se trata de un sentido secundario cuyo significante consiste en un determinado 'tratamiento' de la imagen bajo la acción del creador y cuyo significado, estético o ideológico, remite a determinada 'cultura' de la sociedad que recibe el mensaje" (Barthes, 1986, p. 50).

Se debe tener claridad en cuanto a que el registro no consume la acción, y que esta no se puede dar independiente de aquel. Esto lleva a muchos artistas a dimensionar o reestructurar sus propuestas en pro del medio de registro escogido, y de esta manera establecer diferentes formas de abordar la acción en cada acto que se presente, lo que le posibilita al artista trascender el acto y su documentación.

En el caso del artista Edwin Jimeno, que a pesar de haber desarrollado desde el inicio de su carrera una serie de performance en la cual muchos de los procesos no han sido documentados bajo su aprobación, encontramos que por practicidad ha desplegado de manera alterna una serie de foto-performance, que lo ha llevado a explorar una nueva fase en relación con la forma de abordar y exponer sus acciones performativas, como lo hizo con su obra Pasión dolorosa, que le dio mérito al primer premio en el salón del fuego en 2002.
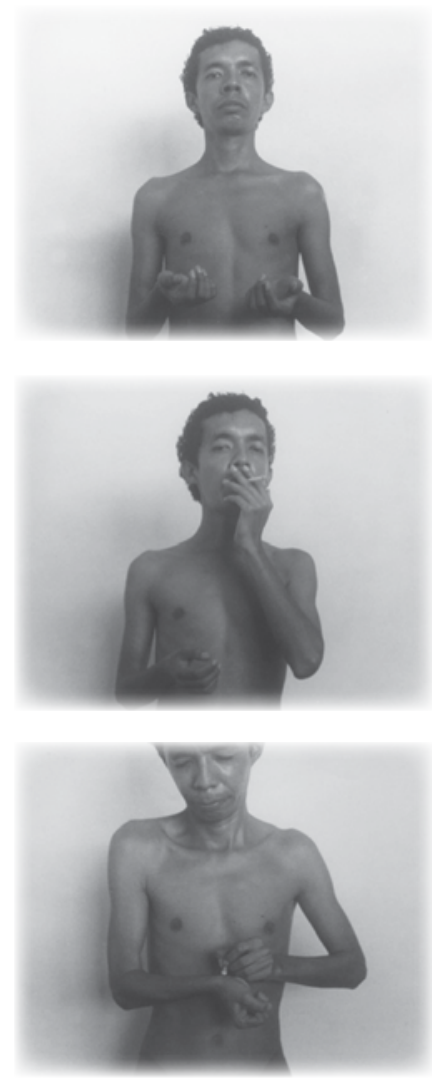
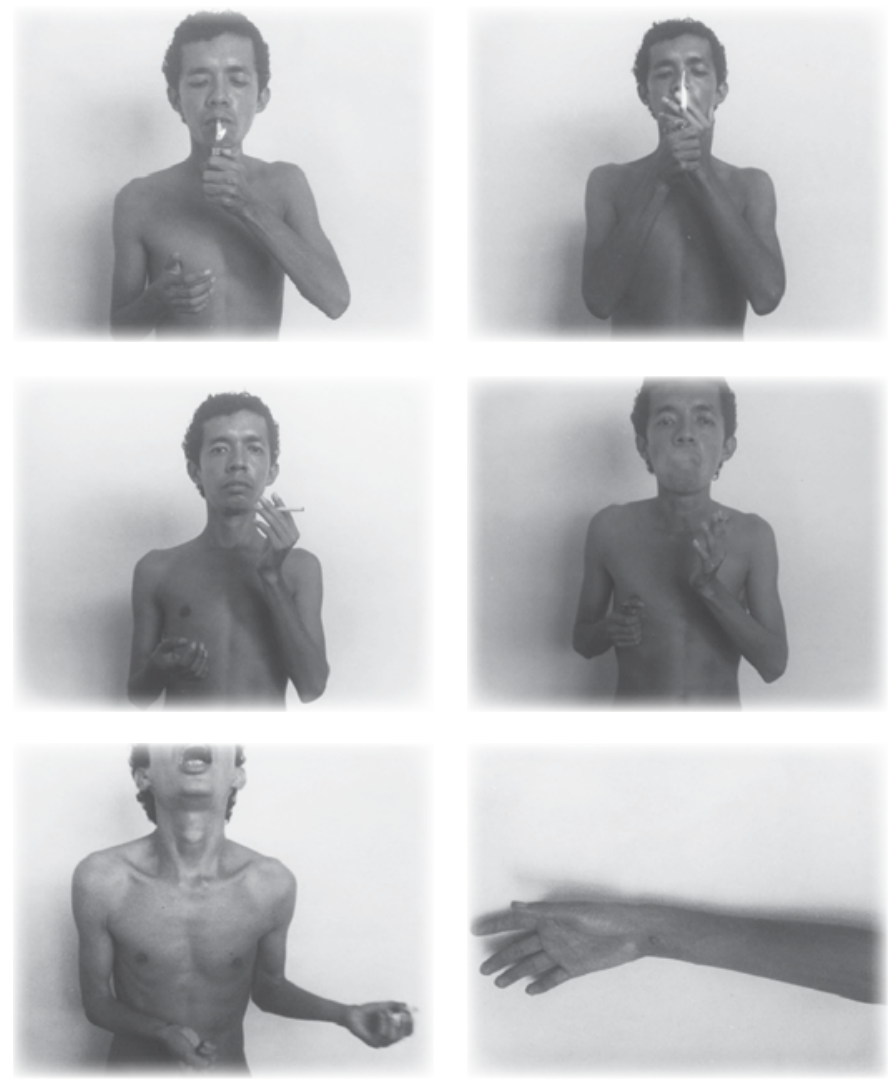
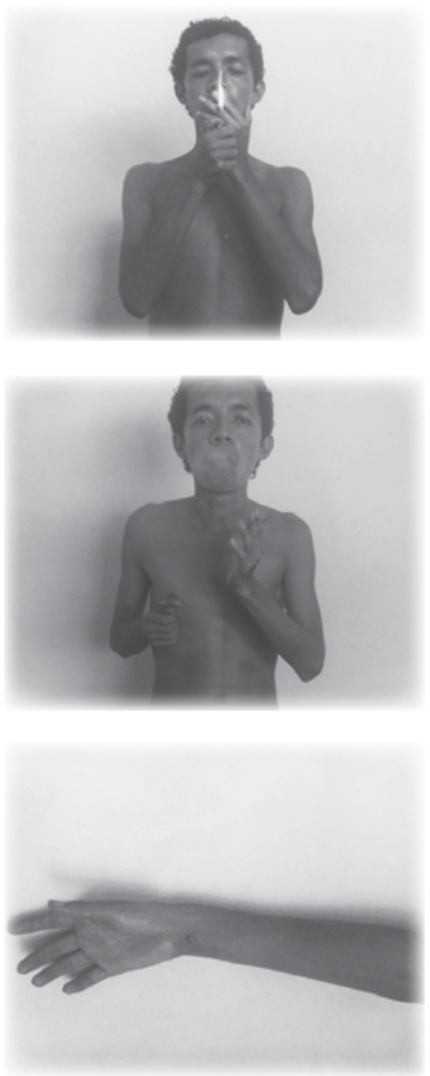
Es de esta manera como podemos apreciar que la fotografía, más que cualquier otra expresión icónica, se nos presenta como una cristalización del instante visual, algo que el ser humano ha perseguido a lo largo de su existencia y que en este momento de nuestra historia es parte fundamental en las reflexiones establecidas frente a su participación dentro de la humanidad como elemento de interpretación del mundo:

Aunque en un sentido la cámara en efecto captura la realidad, y no sólo la interpreta, las fotografías son una interpretación del mundo tanto como las pinturas y los dibujos. Las ocasiones en que el acto de fotografiar es relativamente indiscriminado, promiscuo o modesto no merman el didactismo de todo el empeño. Esta misma pasividad y ubicuidad del registro fotográfico es el "mensaje" de la fotografía, su agresión (Sontag, 2006, p. 89).

Este instante cristalizado es el que permite de manera secuencial no solo apreciar una forma de acción, sino también un acto evolutivo dentro de una propuesta que, más que un hecho performativo convencional (público), se convierte en un registro de estudio (privado), una acción dirigida hacia el fenómeno fotográfico, donde el cuerpo como objeto de estudio y manifestación de una serie de códigos que determinan un tipo de lenguaje entra paradójicamente en una especie de involución. Es decir, tanto el artista del performance, como el fotógrafo establecen en conjunto y a pesar de la autoría del performista una mirada analítica del cuerpo como motivo plástico, un cuerpo que al entrar en un proceso de estudio fotográfico, y en el que se desarrollará posteriormente una edición de imágenes para establecer cuáles son las más apropiadas para exhibir, pasa a un procedimiento materializador de la obra, análogo a los procesos de estudio, análisis, bocetaje, modelado, composición y diseño de cualquier tipo de pintura o escultura que se haya desarrollado en los diferentes momentos de la historia de la humanidad, donde el cuerpo pasa a ser eje idiolecto del artista como ente configurador de realidades. "Se establece una especie de red de formas homólogas que constituyen el código particular de aquella obra, y que resulta una medida muy equilibrada de las operaciones que destruyen el código preexistente, para convertir en ambiguos los niveles del mensaje" (Eco, 2005, p. 67). Esta destrucción de códigos preexistentes que plantea Umberto Eco es lo que permite que en la obra de arte se gesten nuevos códigos en la forma que tiene el artista de plantear su propia realidad. "Esta regla, este código de la obra, es un idiolecto por derecho propio (definiendo idiolecto como el código privado e individual del parlante); de hecho, este idiolecto origina imitaciones, maneras, usanzas estilísticas y, por fin, normas nuevas, como enseña la historia del arte y de la cultura" (Eco, 2005, p. 69).

\section{De la FOtografía COMO DOCUMENTACIÓN Y REGISTRO}

A grandes rasgos podemos establecer que la documentación es una acción en la cual se procesa una información sobre algo con un fin concreto, y el registro se presenta como un conjunto de informaciones relacionadas entre sí con un tratamiento lógico que organiza y constituye una memoria. Estos términos, que se encuentran estrechamente 
relacionados, permiten establecer una conexión entre la fotografía y el performance, ambas como acciones efímeras que se despliegan en una espacialidad y temporalidad diferentes, ya que el tiempo y el espacio en el que el artista desarrolla su obra no es el mismo que el del fotógrafo. Se encuentra en este punto una verdadera relatividad.

La fotografía como documentación o registro arroja una serie de resultados del hecho performativo que se presenta en el acto, pretendiendo desde la óptica del fotógrafo (que se encuentra sujeta a una serie de condiciones que pueden limitar su propia acción, como es el caso del uso del espacio en relación con los espectadores y las condiciones lumínicas) construir la memoria visual de una eventualidad que se pretende preservar para el acceso y contemplación de un público que de momento se encuentra ausente. Tan ausente como la acción captada por la lente del fotógrafo, no pudiéndose desprender el uno de otro; de esta manera la fotografía se vuelve un índice que asume su carácter por la insistente presencia. Sartre plantea que: "Encontramos, pues, en primer lugar una intención dirigida a un objeto ausente. Pero esta intención no está vacía: se dirige a un contenido, que no es cualquiera, pero que, en sí mismo, tiene que presentar alguna analogía con el objeto en cuestión" (1982, p. 13).

Es a través de esta analogía de la cual habla Sartre como se trata precisamente de presentar al espectador una acción que se diluye en el tiempo y se dilata en el espacio; presentarla de manera fragmentada por medio de la imagen captada, tratar de documentar lo más posible aquello que es propio del artista, siendo de esta manera vestigios de una acción o serie de acciones pasadas que calan en la memoria actual. Es decir que la fotografía se nos presenta como un sistema mediato entre el hecho pasado y la acción contemplativa del presente, y le permite así al espectador comprender la importancia de las acciones registradas como parte de las dinámicas del ser humano en relación con la construcción de mundos que se configuran desde un aspecto sociocultural o artístico; de esta manera, se crea un poderoso y productivo documento histórico.

En dicho registro no se puede alcanzar a apreciar el hecho en plenitud, dado que no es solo un fragmento del instante, sino también un fragmento del espacio, siendo importante el punto de vista del espectador frente a un mundo que queda establecido en la imagen. Es así como la fotografía asume su posición configuradora y deliberada ante la realidad, para que esta pueda ser entendida como documento histórico, como registro social; de esta manera la fotografía se convierte en el principal testigo de gran parte de los procesos socioculturales y artísticos.

La fotografía pasa a ser una acción configuradora de realidades, ya que el artista del performance al plantear su obra está automáticamente configurando una realidad que se ve influenciada por su contexto y sus experiencias de vida, mientras que la fotografía asume esa configuración dada por la acción performática y le da un carácter propio al reconfigurarla.

\section{De la Fotografía como RECOPILACIÓN HISTÓRICA Y NARRATIVA}

En este caso la fotografía se presenta como soporte técnico para la recopilación intencional por parte del artista del cuerpo. Esta 
al entrar como dispositivo que recopila un hecho histórico y narrativo deja en el linde la autonomía de las diferentes manifestaciones artísticas que se consideran efímeras o que apelan a la desmaterialización del arte a través del concepto. Con lo anterior se derrumba toda concepción de los artistas modernos de desarrollar un tipo de obra que no fuese museable ni mercantilizable, dada la necesidad de dar a conocer el trabajo propuesto sin tener que realizar nuevamente la acción, y queda así la fotografía en inicios, como mero registro protocolario del acontecimiento, ingresando nuevamente propuestas como el Land Art (en el caso del tipo de obra no museable) y el performance (como un tipo de obra no mercantilizable) a los museos, para complementar su función y legitimación como obra de arte. Así mismo, cambia la visión de comercio del arte por medio de las propuestas emergentes, lo cual genera un proceso de rematerialización de la obra, y de esta forma se convierte el dispositivo fotográfico en un soporte propicio en el cual se difunden, se conservan y se comercializan propuestas que, por lo menos desde el punto de vista discursivo, están sentenciadas a desvanecerse. El performance es una de las varias prácticas artísticas que tienden a este tipo de desmaterialidad, dado que la acción generada por el cuerpo queda en la mente del espectador en una especie de imagen hipnagógica, hecho en el que sería imposible ser gestionada, difundida, comprendida y comercializada la obra de arte.

En este sentido, el performance adquiere una forma de materializarse, y transforma su condición de obra efímera, al tiempo que la fotografía se abre espacio con una especie de retórica del documento; hecho que reafirma un acto que, al ser exhibidas las fotos, se ha acabado.

Encontramos de esta manera que la fotografía ha jugado un papel preponderante dentro del performance como práctica artística, estando en la actualidad la fotografía sujeta al hecho artístico, ya no como un elemento documentario, sino más como un elemento histórico narrativo. De esta manera, se hace, "Difícil considerar la fotografía como un simple documento, registro fiel o memoria detallada del desarrollo de una acción artística, opinión muy extendida que ha condicionado durante demasiado tiempo la valoración de este tipo de prácticas" (Albarrán, 2012, p. 45).

La práctica fotográfica permite tener una imagen mental del acto artístico, el cual no solo es difundido, pues es también un acto controlado por el artista del cuerpo, pero que en cierta medida queda depositada en la obra el carácter del fotógrafo como sujeto que vive la experiencia performativa, como espectador en primer plano, como acto privado, como voyerista. Este es un acto que controlado por el artista permite registrar de manera más detallada la acción en un espacio igualmente apropiado para el desarrollo del mismo.

Estas fotografías no son documentos de una performance desarrollada en público $[\ldots]$, sino imágenes-acciones creadas para y por el objetivo fotográfico...Imágenes que le permiten profundizar en un aspecto muy concreto de su trabajo, en la imagen mental que plantea a partir de un guion-partitura de la acción (Albarrán, 2012, p. 45). 
Es un acto fragmentado donde la obra en cierta medida se edita, en el momento en el que el artista hace una escogencia de las fotos para ser exhibidas, permitiendo a las imágenes indagar en aspectos más concretos del trabajo, donde las gesticulaciones, los movimientos en el espacio y los ángulos escogidos a petición del artistas generan una nueva forma de analizar y comprender el cuerpo como hecho artístico e incluso escultórico. Esto le permite de igual manera al artista explorar la acción desde otro ángulo, ya que el procedimiento escogido por él en relación con el foto-performance admite recesos o retomar movimientos para que estos sean adecuados estableciendo otra línea de trabajo. Esta es en cierta medida una forma reaccionaria frente al mercado del arte, puesto que dentro de este proceso de compra y venta de obras, lo tangible, tienen cierta prioridad.

En el caso de la obra de Edwin Jimeno, $P a-$ sión dolorosa, el artista pone en práctica el foto-performance con el ánimo de ingresar en el salón del fuego donde los premios ofrecidos son de adquisición, es decir, al ganador se le entrega el premio a cambio de la obra. Así vemos como ingresa el acto performativo dentro de un mercado, que se encuentra dirigido a un coleccionismo exigente. En cierta medida la fotografía tiene implícita la capacidad de darle un halo de originalidad a las cosas que pasan por la lente. "La cámara fotográfica contribuye a materializar gestos inmateriales que acaban transformándose en pequeños fetiches: fotografías formalmente imperfectas, cuidadosamente descuidadas, que se han convertido en reliquias anheladas por galerías e instituciones" (Albarrán, 2012, p. 45).
En diversas ocasiones la rigurosidad de la acción performativa ha llevado a condenar el material fotográfico asociado a ella; esto desde un punto de vista en el cual no se presenta una disposición espacial adecuada para establecer un proceso de reafirmación de la acción en curso, mientras que el performance llevado a través de la fotografía o "foto-performance" deja a un lado la experiencia que el espectador obtiene de manera inmediata, para obtener una experiencia mediata, y darle así un espacio a la fotografía para contribuir a las intenciones del artista en relación con el contenido de la obra. En este caso la acción fotográfica frente al acto performativo no se da de manera espontánea, aunque mantenga su instante fugaz; en su defecto se presenta un hecho más circunstancial, una puesta en escena, un monólogo visual, donde la fotografía genera su aporte en la materialidad de la obra y le permite ingresar en un medio donde la reproducción y difusión es fundamental. Como es el caso de las dinámicas de comercio que se manejan en el mercado del arte, a través de galerías, salones de arte donde se ofrecen premios de adquisición, o casas subastadoras, entre otras.

\section{LA INTRODUCCIÓN DEL PERFORMANCE AL MERCADO A TRAVÉS DE LA FOTOGRAFÍA}

Todo elemento que ingrese en una dinámica mercantil es considerado como un bien instrumental, el cual se sujeta a un proceso de oferta y demanda, suponiendo tener un tiempo de vida útil, mientras que la obra de arte es más un bien de consumo, relacionado con un proceso de plusvalía, un bien de consumo con una serie de características 
especiales que trae de manera implícita. Dichas características le permiten establecer un aumento en la economía con el transcurrir del tiempo; esto regido, entre otras cosas, por la durabilidad y unicidad que ofrece la obra de arte.

El suponer que la obra de arte debe tener un contenido único, irreproducible y que está elaborado sobre un soporte duradero o por lo menos que se pueda conservar es una apreciación que en nuestros tiempos genera ciertos debates, ya que muchas de las prácticas artísticas en la actualidad están exentas de dichos parámetros, y se deja a un lado esa concepción de unicidad, reproductividad y perpetuidad. De esta manera, se tiene que:

Algunas obras de arte contemporáneo constituyen bienes tangibles mientras que otras pueden ser consideradas como servicios intangibles. En consecuencia, algunos bienes culturales son bienes de capital o de consumo duradero y generan servicios a lo largo de su vida útil (como un cuadro) mientras que otros (como una performance) solo existen en un momento concreto (Mazuecos, 2008, p. 33).

De una u otra manera, en nuestra sociedad actual regida por un consumismo desmesurado, encontramos las obras de arte convertidas en mercancía, en la cual el valor de cambio ha desplazado la obra de arte desde la calidad, aspecto que determina el valor de la obra, hasta la cantidad, que determina la obra como mercancía. Esto es propio de las características del arte de nuestro presente siglo.

Esa tendencia que pretende la desmaterialización de la obra de arte, la cual se ha convertido en una de las principales características de una parte del arte contemporáneo, no impide (a pesar de lo que se pueda pensar) que se genere un nueva dinámica en el proceso de comercialización de arte. Este hecho ha llevado a que se plantee una reorganización en el sistema de comercio, a redefinir el sistema del arte y por ende las prácticas artísticas del momento. Tal es el caso de las diversas acciones performativas que, entre las múltiples formas de manifestarse, encuentran en la fotografía el medio propicio para el ingreso en el mercado del arte, no solo como registro, sino de este para constituir lo que llamamos foto-performance. De esta forma se asegura el ingreso en el museo a las instituciones que claman por la obra de arte, como aquel elemento en el cual se puede confiar una inversión adecuada dada su condición de materialidad.

Solo a través de la fotografía artistas como Edwin Jimeno han logrado ingresar en las esferas de las instituciones que apuestan a la obra de arte como materialidad. Algo que en cierta medida obliga al artista del cuerpo a replantear su escenario, su espacio, la imagen, la esteticidad de la obra y su pensamiento sobre la condición de lo "efímero", ya que dicha condición cambia automáticamente en el momento cuando la fotografía pasa de ser una mera documentación o registro de una eventualidad a ser un proceso que resguarda una acción que es debidamente escenificada, donde se hace una recopilación intencional y una narración que refuerza las intenciones del artista que pone en práctica el performance y la fotografía.

\section{Conclusiones}

Podemos determinar que aunque el performance como práctica artística está direccionado a procesos que se sustentan desde una 
concepción de inmaterialidad asumiendo su proceso a partir de acciones que quedan en el instante, es decir, que tienden a ser efímeras y confrontadas a una producción artística que está concebida como objeto permanente que está inmerso en un mercado que asume el arte como bien de consumo, no queda, a pesar de los artistas, al margen de ese proceso. Así, algunos artistas encuentran un camino que media entre lo efímero del instante y la permanencia de la materia, la fotografía.

Esto deja un camino abierto para continuar indagando en estos procesos. ¿Cómo se mira el proceso de autoría entre el artista del performance y el artista fotógrafo? ¿De quién es realmente la fotografía? ¿Cómo son los acuerdos respecto a este asunto? ¿Qué tanto influye el fotógrafo en las acciones del performista en el momento de generar el registro de la acción? Estos son algunos de los interrogantes que permitirán continuar con una investigación que ayude a seguir comprendiendo el fenómeno del arte y sus implicaciones como discurso que se sustenta en la realidad del ser humano.

\section{ReFERENCIAS}

Albarrán, J. (2012). Del fotoconceptualismo al ototableau. Fotografía, performance y escenificación en España. Salamanca: Universidad de Salamanca.

Barthes, R. (1986). Lo obvio y lo obtuso. Barcelona: Paidós.

Eco, U. (2005). La estructura ausente. México, D. F.: DeBolsillo.

Mazuecos, A. (2008). Arte contextual: estrategias contra el mercado del arte contemporáneo. Granada: Universidad de Granada.

Pabón, C. (2000). Actos de fabulación. En Investigaciones sobre arte contemporáneo en Colombia. Proyecto pentágono. Bogotá: Ministerio de Cultura.

Sartre, J.-P. (1982). Lo imaginario: psicología fenomenológica de la imaginación. Buenos Aires: Losada.

Sontag, S. (2006). Sobre la fotografía. México, D. F.: Santillana.

Sotelo, M. R. (2000). Introducción. En Investigaciones sobre arte contemporáneo en Colombia. Proyecto Pentagono. Bogotá: Ministerio de Cultura. 